\title{
(In) Segurança Alimentar: experiência de grupos focais com populações rurais do Estado de São Paulo
}

\author{
Maria de Fátima Archanjo Sampaio ${ }^{1}$, Anne W. Kepple², Ana Maria Segall-Corrêa ${ }^{3}$, \\ Julieta T. A.de Oliveira ${ }^{4}$, Giseli Panigassi ${ }^{5}$, Lucia Kurdian Maranha ${ }^{6}$, Letícia Marin-Leon ${ }^{7}$, \\ Sônia M. P. P. Bergamasco ${ }^{8}$ e Rafael Perez-Escamilla ${ }^{9}$
}

O presente trabalho apresenta a experiência de grupos focais com participantes oriundos de populações rurais do Estado de São Paulo, que possibilitou analisar e elucidar a compreensão existente acerca dos conceitos utilizados pela Escala Norte-Americana para Medida de Segurança Alimentar (USDA Core Food Security Module, hoje denominada Household Food Insecurity Access Scale - HFLAS), previamente adaptada e validada para populações brasileiras urbanas. Essa fase qualitativa antecedeu e forneceu subsídios para realização da fase quantitativa do estudo de validação dessa escala para populações rurais. Foram realizados dois grupos focais, compostos, cada um, por 12 participantes, escolhidos e convidados para representar diferentes categorias da população rural paulista, incluindo: assentados, agricultores familiares tradicionais, trabalhadores assalariados e quilombolas. Os conceitos e palavras-chave investigados foram: "Segurança alimentar"; "Qualidade da alimentação"; "Alimentação saudável"; "Alimentação variada"; "Alimentação saudável e variada"; "Alimento suficiente"; "Condições para ter alimento suficiente: trocas, reserva, estoque, produção de alimentos para consumo e compra de alimentos"; "Dinheiro suficiente"; "Ficar sem nenhum dinheiro"; "Insegurança alimentar" e "Fome". Os participantes expressaram uma compreensão abrangente sobre segurança alimentar, englobando diferentes aspectos do tema. A análise dos depoimentos desses grupos focais apontou para o reconhecimento no conceito de segurança alimentar do direito humano à alimentação, o que envolve também questões como acesso ao trabalho, saúde, educação, moradia e renda. Na compreensão do termo "Qualidade da alimentação" ficou evidente a preocupação com o consumo de produtos sem agrotóxicos, tendo sido observadas, em menor escala, referências às questões de preço e aparência mais recorrentes nos grupos focais com populações urbanas. Os resultados conduziram a modificações no questionário e contribuíram para o desenvolvimento da Escala Brasileira de Insegurança Alimentar (EBIA), válida para diagnosticar essa condição e monitorar o impacto de políticas voltadas para o combate à fome no país. O processo de validação concluído permitiu o uso da escala brasileira em projetos de pesquisa sobre segurança alimentar que atenderam a um edital do CNPq, ainda em 2003, e posteriormente, essa escala foi incorporada ao suplemento de segurança alimentar da Pesquisa Nacional por Amostra de Domić́lios (PNAD-2004), do Instituto Brasileiro de Geografia e Estatística (IBGE).

\section{Food (In) Security: findings from focus groups in rural areas in the state of São Paulo, Brazil.}

We conducted focus groups in rural areas in the state of São Paulo to check the understanding of the language and concepts used in the 18-item USDA Core Food Security Module, previously validated for urban Brazilian populations. This qualitative phase informed a subsequent quantitative phase of the validation study. Two focus groups were conducted, composed of 12 participants each, purposefully selected to represent São Paulo's rural population, including: traditional family farmers, salaried farm workers, beneficiaries of agrarian reform programs, and farmers from communities of former slaves

\footnotetext{
${ }^{1}$ Pesquisadora Doutora - Departamento de Medicina Preventiva e Social - DMPS - FCM - UNICAMP - E-mail: fatimafajardo@terra.com.br

${ }^{2}$ Doutora - Pesquisadora colaboradora voluntária - Departamento de Medicina Preventiva e Social - DMPS - FCM - UNICAMP

${ }^{3}$ Professora Doutora - Departamento de Medicina Preventiva e Social - DMPS - FCM - UNICAMP

${ }^{4}$ Pesquisadora Doutora - Conselho Integrado de Planejamento e Gestão - CIPG - FEAGRI - UNICAMP

${ }^{5}$ Pesquisadora Doutora - Departamento de Medicina Preventiva e Social - DMPS - FCM - UNICAMP

${ }^{6}$ Pesquisadora Doutora - Departamento de Medicina Preventiva e Social - DMPS - FCM - UNICAMP

${ }^{7}$ Pesquisadora Doutora - Departamento de Medicina Preventiva e Social - DMPS - FCM - UNICAMP

${ }^{8}$ Professora Titular - Conselho Integrado de Planejamento e Gestão - CIPG - FEAGRI - UNICAMP

${ }^{9}$ Professor - Departament of Nutrition and Latino Health Disparities NIH EXPORT Center (P20MDOO 1765)

University of Connecticut - UCONN - EUA
} 
(In) segurança alimentar: experiência de grupos focais, Sampaio et al.

(quilombolas). Key phrases explored included “enough food”, “enough money”, "healthy diet”, "dietary quality”, "balanced meal", "food insecurity", and "hunger". Participants expressed a broad understanding of food security as being a human right involving access to work, health, education, housing, and income. Their conceptualizations of dietary quality differed somewhat from their urban counterparts, with the former referring more to the consumption of organic produce, while the latter emphasized the appearance and price of food. Results led to modifications in the module, and contributed to the development of a valid scale for monitoring the impact of policies being implemented to combat hunger in Brazil. The Brazilian Food Insecurity Scale - EBLA was recently included as a supplement to the National Household Survey of the Brazilian Institute of Geography and Statistics (IBGE).

\section{Introdução}

Este trabalho integra a pesquisa denominada "(In) Segurança alimentar no Brasil: validação de metodologia para acompanhamento e avaliação"10. O objetivo dessa pesquisa mais abrangente foi disponibilizar para o Brasil um método de avaliação da insegurança alimentar e fome, no âmbito familiar, por meios diretos, tendo como modelo a escala norte-americana (USDA Core Food Security Module $)^{[1]}$, que tem sido utilizada na Current Population Survey (Pesquisa Populacional Atual) dos Estados Unidos da América desde 1995. O desenvolvimento dessa escala foi motivado por crescente preocupação com a fome naquele país, tida como uma questão política importante, especialmente numa época de cortes de verba para programas assistenciais governamentais, como o Programa de Cupom Alimentação (Food Stamp Program). Em um resumo descrevendo as experiências de mais de 20 anos de história do desenvolvimento da escala norte-americana de medida da insegurança alimentar e fome, Bickel et al. ${ }^{[2]}$ referiram o decreto de 1990 do Congresso Americano sobre o Monitoramento Nacional da Nutrição e Pesquisas Relacionadas, o que demandou o desenvolvimento de uma ferramenta confiável de medição da fome nos EUA. Em 1994, vários órgãos governamentais colaboraram na organização da Conferência Nacional de Pesquisa e Mensuração da Insegurança Alimentar, com o objetivo de discutir as bases conceituais para medir a fome e a insegurança alimentar, além de firmar um acordo de trabalho sobre o melhor método para incorporar tal medida nas pesquisas nacionais ${ }^{[3]}$. Nessa conferência, tomando como base vários trabalhos científicos realizados durante os anos 80 e começo dos anos 90 [4, 2, 5, 6, 7, 8, 9], foi possível criar a Escala Norte-Americana de Medida da Segurança Alimentar (USDA Core Food Security Module).

No Brasil, em 2004, a II Conferência Nacional sobre Segurança Alimentar e Nutricional avançou na conceituação de segurança alimentar e nutricional ao defini-la como "a realização do direito de todos ao acesso regular e permanente a alimentos de qualidade, em quantidade suficiente, sem comprometer o acesso a outras necessidades essenciais, tendo como base práticas alimentares promotoras de saúde, que respeitem a diversidade cultural e que sejam social, econômica e ambientalmente sustentáveis" ${ }^{[10]}$.

Mesmo cientes de que a escala norte-americana não apresenta a mesma abrangência conceitual da definição do CONSEA, os pesquisadores envolvidos na pesquisa mencionada no início desta introdução julgaram que era de interesse validá-la para o Brasil. Naquele momento, tal opção se justificava pelo fato de ser esse um instrumento de medida direta de insegurança alimentar no âmbito domiciliar e, também, por conhecerem-se as experiências de sua aplicação em diversas populações ${ }^{[11]}$.

Assim, as atividades de campo da pesquisa de validação da Escala Brasileira de Insegurança Alimentar - EBIA ocorreram entre os meses de abril de 2003 e fevereiro de 2004, em municípios dos estados de São Paulo, Goiás, Paraíba, Amazonas e Mato Grosso. As atividades incluíram procedimentos qualitativos que

\footnotetext{
${ }^{10}$ Esta pesquisa foi coordenada pelo Departamento de Medicina Preventiva e Social da Faculdade de Ciências Médicas da Universidade Estadual de Campinas - FCM / UNICAMP, com o apoio financeiro e técnico do Ministério da Saúde, da Organização Pan-Americana de Saúde - OPS / Brasil, do Ministério do Desenvolvimento Social e da Fundação de Amparo à Pesquisa do Estado de São Paulo
} 
forneceram subsídios para procedimentos quantitativos em populações urbanas e, em um segundo momento, também em populações rurais ${ }^{[12]}$.

A etapa qualitativa, nos cinco estados referidos, foi realizada inicialmente com quatro painéis de especialistas, que deram as diretrizes mais gerais aos trabalhos subseqüentes, e onze grupos focais, urbanos e rurais ${ }^{[13]}$.

Os procedimentos quantitativos que se seguiram constituíram-se de estudos populacionais, tendo por base amostras selecionadas de forma intencional e aplicação, nos cinco estados, dos questionários previamente elaborados e pré-testados.

A EBIA consiste na formulação de perguntas diretamente a uma pessoa da família, por meio de um questionário estruturado, visando captar a percepção da segurança e insegurança alimentar. A insegurança alimentar medida pela escala apresenta-se em um gradiente de severidade, iniciando pelo receio da pessoa de que a família venha a sofrer privação alimentar no futuro próximo, passando pelo comprometimento da qualidade da dieta e pela limitação da quantidade de alimentos consumidos no domićlio, chegando até o nível mais grave da insegurança alimentar, que é fome entre adultos e/ou crianças da família.

A partir da somatória do número de respostas positivas às questões e pontos de corte preestabelecidos, obtêm-se esses gradientes de (in) segurança alimentar, conforme explicado no Quadro 1, a seguir.
Neste contexto, o presente trabalho tem como objetivo apresentar a experiência dos grupos focais realizados com populações rurais do Estado de São Paulo, procurando elucidar qual é a compreensão dos participantes sobre os conceitos relacionados à (in) segurança alimentar contidos na EBIA.

\section{Material e métodos}

\section{Definição de categorias de populações rurais para composição da amostra}

Para a validação de um questionário que fosse capaz de considerar a situação de segurança, insegurança alimentar e fome das diferentes populações rurais brasileiras, foram necessários procedimentos que garantissem que essas famílias teriam o mesmo entendimento sobre o significado de cada uma de suas perguntas. Nesse sentido, as opções de respostas às perguntas deveriam contemplar, também, a intensidade com que se experimenta insegurança alimentar na diversidade rural do país.

Com o projeto aprovado pela Comissão de Ética da FCM-UNICAMP (№ 355/2003), a primeira etapa do processo de validação rural iniciou-se durante o "Seminário Nacional para Análise e Adequação de Instrumento de Medida de Segurança Alimentar em Populações Rurais", realizado na Universidade Estadual de Campinas (UNICAMP), reunindo especialistas das cinco regiões estudadas. O objetivo desse seminário foi, num primeiro momento, o de evidenciar as principais características da população do novo estudo, destacando-se as diferenças, em relação à população

Quadro 1. Gradiente de (in) segurança alimentar da Escala Brasileira de Insegurança Alimentar (EBIA).

1. Segurança alimentar - Todas as respostas aos itens da EBIA são negativas. Neste caso não há problema de acesso aos alimentos em termos qualitativos ou quantitativos e não há preocupação de que os alimentos venham a faltar no futuro.

2. Insegurança alimentar leve - De uma a cinco respostas positivas aos itens. Há preocupação com a falta de alimentos no futuro próximo e arranjos domésticos para que os alimentos durem mais.

3. Insegurança alimentar moderada - De seis a dez respostas positivas aos itens. Nesta situação há comprometimento da qualidade da alimentação, na busca de manter a quantidade necessária. Neste nível da insegurança, inicia-se a redução da quantidade de alimentos entre os adultos da família.

4. Insegurança grave - De onze a quinze respostas positivas. Condição em que há restrição da quantidade de alimentos, levando à situação de fome entre adultos e crianças da família. 
(In) segurança alimentar: experiência de grupos focais, Sampaio et al.

urbana, que pudessem representar vantagens ou limitações à garantia de segurança alimentar familiar, para em seguida sugerir adaptações no instrumento já validado na área urbana, além de recomendar os indicadores que poderiam ser utilizados na validação externa nesse novo contexto.

Em síntese, a questão central que se colocava era: é possível ter um único instrumento, com validade preditiva para medida de (in) segurança alimentar, tanto para populações rurais quanto urbanas?

Da análise sobre as especificidades da população rural em relação à urbana sobressaiu a questão da possibilidade de acesso à terra pela primeira e, com isso, a sua possibilidade de produzir alimentos para auto-consumo e/ou consumir os excedentes não comercializados das safras. Nesse caso, e sob as mesmas condições de ingresso monetário, se poderia formular a hipótese simplificada de que o risco à insegurança alimentar e fome seria menor para as famílias rurais do que para as urbanas. No entanto, não é esta uma questão simples. Por um lado, porque nem toda população rural brasileira tem acesso à terra, pois muitos são os assalariados no campo que, mesmo tendo sua moradia na zona rural, não têm a propriedade ou posse de terra que possibilite autonomia para sua exploração. Por outro lado, mesmo tendo uma área para plantar, alguns agricultores se encontram tão endividados que sequer podem comprar sementes; tantos outros não conseguem irrigar suas lavouras porque o regime hídrico local é naturalmente deficitário e o acesso aos açudes construídos é, muitas vezes, socialmente excludente. Várias outras realidades poderiam ser aqui citadas, assim como ocorreu no referido Seminário; entretanto optou-se, neste trabalho, por evidenciar apenas essas, com o intuito de exemplificar a escolha das categorias de populações rurais para a validação da escala de medida da I.A e fome nesse meio e em cada uma das cinco regiões do país. Para o estado de São Paulo, foi escolhida a seguinte composição para os grupos focais: agricultores familiares tradicionais; assalariados rurais; assentados de projetos de reforma agrária e quilombolas.

\section{Procedimento}

Em relação às apreciações do grupo de especialistas sobre o instrumento de coleta de dados, feitas durante o mencionado seminário, vários conceitos e palavras-chave foram destacados para serem discutidos com os participantes dos grupos focais, representando as categorias de populações rurais escolhidas. Foram eles: Segurança alimentar; Qualidade da alimentação; Alimentação saudável; Alimentação variada; Alimentação saudável e variada; Alimento suficiente; Condicões para ter alimento suficiente: trocas, reserva, estoque, producão de alimentos para consumo e compra de alimentos; Dinheiro suficiente; Ficar sem nenbum dinheiro; Insegurança alimentar e fome.

\section{Técnicas de grupos focais}

O grupo focal é um método de pesquisa qualitativa que vem sendo adotado nas ciências sociais e na área da saúde há mais de duas décadas: Scrimshaw \& Hurtado ${ }^{[14]}$, Morgan ${ }^{[15],[16]}$; Kreuger ${ }^{[17]}$, Westphal et al. ${ }^{[18]}$, Kitzinger ${ }^{[19]}$, Gibbs ${ }^{[20]}$, Minayo [21]. O método envolve entrevistas coletivas com grupos de aproximadamente seis a doze pessoas, que tenham em comum características-chave relativas ao tema da pesquisa e objetivando compreender opiniões, sentimentos, percepções, atitudes e experiências relacionadas a temas de interesse para os pesquisadores.

Além de alcançar um número maior de pessoas em relação às entrevistas individuais, outra vantagem do grupo focal é a interação espontânea entre os participantes, fato que provoca, muitas vezes, respostas emocionais e que, também, incentiva as conversas mais espontâneas sobre experiências e atitudes comuns. Essa interação é uma característica importante do grupo focal, que o destaca de outros tipos de entrevista grupal ${ }^{[16]}$. O grupo focal é particularmente útil quando existem diferenças de poder entre participantes e profissionais ou gestores, quando a linguagem cotidiana e a cultura de um grupo específico são de interesse para a pesquisa ou, ainda, quando interessa investigar o nível de consenso sobre um dado tópico ${ }^{[20]}$.

Os participantes estão inseridos em um contexto sócio-histórico comum e, em alguma medida, sem excluir os conflitos, partilham de valores, linguagem e práticas sociais. Em linhas gerais, o participante do grupo é concebido desde o início como um sujeito social, cujas formas de compreender o mundo e de se compreender no mundo são construídas em interação e comunicação social ${ }^{[22]}$. 


\section{Os grupos focais realizados em Campinas}

Foram realizados dois grupos focais com doze pessoas em cada um. Seguindo o padrão preconizado, cada grupo focal contou com um moderador treinado para incentivar e assegurar a participação livre e espontânea de todos, sem divergir muito dos temas previamente definidos sob forma de perguntas abertas. Dois observadores ajudaram o moderador, anotando todas as suas observações sobre a dinâmica do grupo, inclusive em relação à linguagem não-verbal, à participação ou não dos membros do grupo e às ações do próprio moderador, com o intuito de identificar possíveis influências nos dados produzidos. Cada grupo ainda contou com um relator de álbum seriado (flip-chart) para anotar as observações do grupo e compartilhá-las com todos os participantes.

Diferentes comunidades rurais paulistas foram representadas: agricultores familiares tradicionais e assalariados rurais de Espírito Santo do Pinhal, agricultores provenientes de dois assentamentos rurais localizados nos municípios de Sumaré e MogiMirim e representante da comunidade quilombola do Vale do Ribeira. Os integrantes foram convidados para participação voluntária. A equipe da UNICAMP providenciou refeições e transporte para todos e hospedagem para aqueles das regiões mais distantes.

No dia do evento, os participantes foram recebidos com um café da manhã, que se configurou num primeiro momento de confraternização antes do início das atividades da pesquisa.

Após o café, todos os participantes foram reunidos numa sala ampla, onde cada um pôde apresentar-se para os demais e, para facilitar a integração e a espontaneidade da comunicação, realizou-se um jogo psicodramático, descrito no Anexo 1.

Os trabalhos dos grupos focais foram divididos em duas etapas. A primeira envolveu a discussão dos conceitos e palavras-chave contidos na escala e a segunda foi a leitura do questionário para sua compreensão e adequação de linguagem. Antes de dar início ao grupo focal, foi solicitada autorização para filmar as sessões, e todos os presentes registraram verbalmente seu consentimento. A filmadora ficou ligada, apontando ao centro da sala e para o álbum seriado; portanto, o equipamento não foi motivo de inibição.

Os conceitos e palavras-chave foram previamente escritos em cartões, de maneira clara, com letras grandes. Estes foram lidos em voz alta para completo entendimento de todos, inclusive aqueles sem domínio de leitura e escrita, e colocados, um por um, no meio do círculo dos presentes, para discussão. A cada cartão colocado foi solicitado aos participantes que expressassem seu entendimento a respeito, tendo os coordenadores o cuidado de garantir a manifestação de todos. Vale lembrar que a ordem de apresentação dos conceitos se deu de tal forma que os mais conhecidos foram os primeiros a serem abordados, facilitando o entendimento da dinâmica e a interação dos membros do grupo. É importante salientar que, para cada conceito, os respectivos depoimentos eram anotados no álbum seriado, para que todos os participantes pudessem revisá-los ao final de cada rodada, por meio de leitura feita pelos coordenadores.

\section{Análise dos dados}

Os dados analisados foram aqueles das anotações do álbum seriado e das transcrições das gravações em vídeo, complementadas pela revisão e análise das anotações dos observadores e sua discussão preliminar pelos coordenadores, observadores e relatores dos grupos focais.

As fitas de vídeo, além de registrarem as falas para as análises, possibilitaram aos pesquisadores maior familiaridade com os conteúdos, facilitando a identificação dos diferentes temas de cada questão, sua compreensão e posterior organização das experiências de vida apresentadas pelos participantes do grupo focal.

\section{Resultados}

Conforme os depoimentos se tornavam mais espontâneos, os grupos adquiriam mais confiança e interesse nas próprias falas. Mais à vontade, os participantes compartilhavam suas experiências de vida no campo, de modo que os entendimentos do grupo sobre os conceitos e palavras-chave foram sendo aprofundados.

Os resultados relativos a esses conceitos e palavras-chave pelos dois grupos focais de Campinas estão descritos a seguir, na mesma ordem em que 
(In) segurança alimentar: experiência de grupos focais, Sampaio et al.

foram apresentados nos grupos focais. Em alguns itens foram tecidas comparações com os depoimentos dos grupos focais urbanos.

\section{Segurança alimentar}

"É a pessoa conseguir ter alimentação para ela sobreviver melhor [...] Procurei passar para os meus filhos o que minha mãe me ensinou... É a base para o bem das pessoas";

“[...] então, segurança alimentar é moradia, educação";

"[...] pois é, acho que é tudo isso aí, um direito de ter essas coisas, né"

O conceito "Segurança alimentar" para os participantes desses grupos focais estava diretamente relacionado com o "acesso às condições de trabalho, saúde, educação, habitação e renda", bem como com "Direito à alimentação". Além das associações estabelecidas em relação à "quantidade adequada" da alimentação, mencionaram também a importância de aspectos da "qualidade"; "condições de acesso diário e de qualidade", principalmente em relação à "produção de alimentos com qualidade". O papel da educação nutricional para tornar conhecido "o que é bom para a saúde" também foi mencionado, inclusive com depoimento relacionado à importância do "hábito alimentar em todas as fases da vida", ressaltando a necessidade de garantir isso para as crianças, "desde quando elas estão na barriga da mãe". Também foi mencionada a associação desse conceito com alimento seguro (higiene, qualidade, procedência, validade); entretanto essa associação esteve muito mais presente nos grupos focais realizados com a comunidade urbana.

\section{Qualidade da alimentação}

Nas áreas rurais "Qualidade da alimentação" parece menos relacionada às questões de aparência e de preço muito enfatizadas pelos grupos focais das áreas urbanas. A expressão apareceu nas discussões da comunidade rural mais relacionada ao consumo de vegetais e suas procedências: "coisa boa". Nesse sentido, apareceram menções aos produtos orgânicos, sem veneno, sem agrotóxicos, como por exemplo:

"Na hortinha lá de casa, só usamos esterco",
"O que nos queremos (é) definir um alimento de qualidade, se ele é bonito, se ele tem o sabor palatável ou se ele alimenta, (se) é nutritivo, não é isso? Porque às vezes você tem um produto, e aí ele está bonito, mais aí você vai fazer..., você pega ele e vai no laboratório e vai achar o quanto de agrotóxico ele não tem..."

Também foram associados a esse conceito mais genérico depoimentos como "Consumo moderado e equilibrado" e "aquele que não prejudica a saúde".

\section{Alimentação saudável}

Assim como nos grupos das áreas urbanas, o primeiro depoimento sobre "Alimentação saudável" diz que "esse é o tipo de alimentação que não faz mal à saúde". Também foi dito que esse conceito deve ponderar o equilíbrio entre o consumo de vários grupos de alimentos: qualidade e quantidade:

"Acho que alimentação saudável é você balancear ela, né... vai atrás de alimentos de boa qualidade, procedência, e não exagerar, né... porque o exagero faz mal, acho que saudável, né, é ter um certo equilíbrio ... tem que ter equilíbrio na alimentação".

Nas comunidades rurais, surge a referência ao alimento natural no lugar do industrializado. Além dessa referência, também foram mencionadas as maiores possibilidades que a área rural tem para oferecer uma "diversificação de alimentos" e para "processar alimentos com mais amor e cuidado", lembrando sempre da necessidade de um "planejamento da aquisição destes em todas as fases do ano". De maneira geral, esses depoimentos mostraram o importante vínculo existente entre o trabalho dos agricultores e suas expectativas em relação à alimentação e saúde. O depoimento que faz referência à necessidade de um "acesso contínuo à educação para a alimentação" também ilustra isso.

\section{Alimentação variada}

Para o conceito "Alimentação variada", a concepção da comunidade rural é bem próxima àquela do mencionado no meio urbano: "necessidade de consumir vários tipos de alimentos". A maior diferença, no entanto, está relacionada à maneira de preparar os alimentos "para não enjoar". Por causa da época de abundância de determinado produto, é importante saber prepará-lo de diversas maneiras: "farinha de mandioca, tapioca, biju, mandioca 
assada, frita, em sopa, doce", por exemplo, e "com muito amor". Vale ressaltar que, além das variedades de preparo de um mesmo alimento, foi exposta a importância da combinação das cores para obtenção, na medida do possível, de maior diversificação do consumo.

"Acho que (alimentação variada) é o arroz, o feijão e a gente tem que ter as outras cores né, a gente tem que saber combinar as cores: verde, amarelo, vermelho".

A educação para um bom hábito alimentar também foi lembrada aqui, por exemplo, quando foi dito "que a melhor maneira de aprender a consumir os alimentos é através da preparação deles".

\section{Alimentação saudável e variada}

Quando formulada a questão aos grupos sobre o que eles entendiam por "Alimentação saudável e variada", ou seja, quando se juntaram os dois últimos conceitos discutidos em um único, as respostas registraram que esse conceito duplo significava um "correto equilíbrio entre o que você tem necessidade de consumir". Esse foi um ponto polêmico, pois a discussão apontava para o fato de que na verdade eles "sempre variavam seu cardápio de acordo com aquilo que tinham disponível para o consumo", apesar de entenderem a importância dessa diversificação que ficou mais clara posteriormente. Nessa subseqüente oportunidade de discussão do conceito apareceram depoimentos, tais como: "Alimentação sem veneno, de boa procedência", "Com vários alimentos", "Com muita verdura, legumes e pouca carne vermelha”, "Aquela que a gente se sente bem", "Diversificada com aquilo que se tem". Vale lembrar que uma discussão sobre o termo "alimentação balanceada" também foi realizada, mostrando-se esse conceito "mais empregado por médicos e nutricionistas", que eles têm acesso pela TV, e que "parece estar mais relacionado com o que o organismo do ser humano aproveita da alimentação".

\section{Alimento suficiente}

Nos grupos urbanos, a discussão sobre o entendimento de "Alimento suficiente" esteve muito relacionada com uma escassez emergente. Naquela ocasião foi dito que o conceito de "suficiente" era aquilo que "dava para passar o mês", e também que, para as famílias, o disponível estava abaixo do suficiente e isso tinha muita relação com as despesas de aluguel, luz, água, remédios, emergências que competiam com a prioridade dos alimentos. Já nos grupos focais da área rural, a esse conceito não foi atribuída a mesma ênfase no que diz respeito ao acesso, embora isso também tenha sido mencionado ao longo da discussão, como por exemplo:

"[...] eu acho que qualquer cidadão tinha que ter o suficiente pra se manter, eu tenho alguns amigos que falam, né... puxa vida eu trabalho o dia inteiro, a semana inteira e não sobra nem pra eu comer!'

Foi dito também que "Alimento suficiente" era entendido como a quantidade adequada para manter o organismo forte e saudável, mas que, quando se tem menor possibilidade de acesso aos alimentos, "a alimentação suficiente é mais regrada". Para as comunidades rurais, esse conceito estava mais relacionado à quantidade planejada para o período, principalmente em relação à questão da produção e da safra.

Condiçoes para ter alimento suficiente: trocas, reserva, estoque, produção de alimentos para consumo e compra de alimentos

Levando em consideração esses conceitos, os participantes mostraram como são importantes algumas estratégias alternativas para suas populações e que a situação no campo, quando comparada àquela na cidade, se revela muitas vezes melhor, pois vários participantes dos grupos focais tinham alguma experiência de vida urbana, ou tinham parentes morando em grandes cidades. Eles comentaram que compravam alimentos e, portanto, também dependiam de dinheiro, apesar de produzirem para o consumo próprio. O problema é que tudo isso se relacionava com o preço de venda dos produtos, que pouco remunera o produtor. A necessidade de políticas públicas destinadas à melhoria das condições de crédito e produção foi repetidamente mencionada.

"A gente fica com mais dificuldade para pagar o financiamento, porque lá não aceita frango, nem milho. É em real, então não tem jeito de chegar lá e pagar, a gente negocia, mas se aceitasse porco eu pagava todas as contas".

A possibilidade de possuir um "silo para guardar 
(In) segurança alimentar: experiência de grupos focais, Sampaio et al.

o milho", por exemplo, foi mencionada como uma forma de se dispor de estoque equivalente a ter "O dinheiro em poupança".

A diferença que os participantes destacaram em relação a quem vive na cidade se relaciona ao fato de poderem, de forma coletiva, resolver muitos de seus problemas. Por exemplo, os quilombolas fazem compras coletivas e mencionam a questão da troca de alimentos como uma herança importante deixada por seus antepassados. Os assentados também estabelecem trocas, que classificam como "política de boa vizinhança". Não gostam muito de solicitar as coisas para o vizinho, mas sempre que têm algo em abundância, dividem entre si. Além disso, plantam o arroz e o feijão, para consumo ao longo do ano, e o milho, que serve de ração para os animais. A própria horta de casa é a reserva para o mês. Foi dito que:

"Antes, o arroz tinha um preço tão baixo que não compensava produzi-lo, era mais fácil comprar no mercado. Hoje o preço dele no mercado é inviável e por isso, o assentamento reviu sua estratégia e está plantando arroz para o consumo do ano";

“Meu pai tem lá uns pés de café né, eu penso que a reserva é também a verdura né, eu planto lá alface, daqui a 30 dias você vai colher, então quando você começar a colher aquele, você já planta outro entendeu... Arroz, feijão dá pra guardar né, eu tenho família pequena, eu e meus filhos [...]"

Trabalhos alternativos, como a produção de artesanatos, tais como: "tapetes, biscoitos, pães caseiros", ou ainda, a preparação de palestras e refeições para visitantes, dentre outros, mostram quão grandes são os esforços realizados. Percebe-se que as populações rurais possuem uma expectativa em relação a seu futuro mais ao alcance de suas próprias mãos.

Vale lembrar que esse não é bem o caso dos depoimentos dos assalariados rurais, que se vêem sozinhos para resolver seus problemas com a alimentação, e sua grande expectativa, assim como das populações urbanas, está totalmente relacionada ao salário mensal:

"Pra gente não existe isso aí, é só o salário mínimo e boa [...]"

\section{Dinheiro suficiente}

O conceito "Dinheiro suficiente" não era necessariamente um valor definido em reais, mas sim um valor que viabilizasse não apenas a alimentação, mas também a realização de outros gastos familiares essenciais, alguns deles relacionados à exploração produtiva da terra:

"Para alimentação, calçado, um milhão de coisas, remédio que você necessita, eu não sei o que seria dinheiro suficiente, eu coloco um ponto de interrogação aí...”

"Eu devo 3 mil reais pro PRONAF, é eu poder pagar ele sem dificuldade"

"Na medida que a gente pega o financiamento, investe na produção, (dinheiro suficiente) é o retorno pra você pagar o financiamento e sobrar alguma coisa pra você né, pra você fazer aquilo que você quer fazer, trocar o carro, aumentar a casa, fazer uma viagem"

"Acho que tem que ser o básico, tem que ser que nem ela falou de 500 reais, 600 , tem que ser uma coisa básica".

"Dinheiro para fazer uma compra todo mês [...] você pode comprar um remédio, (pagar a ) conta de água, porque se você não pagar a conta de luz, vão cortar né".

"É a gente ter uma alimentação básica e também estudo pros filhos, eu tenho 3 filhos estudando [...] se o homem tem um salário de 500 reais dá pra fazer tudo isso aí."

"Condições de salário para ter o alimento certo né, nossa constituição fala que todo brasileiro tem o direito de passar bem né, de se alimentar bem, o salário mínimo tem que ser suficiente pra isso [...]".

“[...] não é pra ficar rico, é pra comer".

Esse conceito pareceu semelhante para as populações rurais e urbanas. A maior diferença que se nota é que para as comunidades rurais, depois dos depoimentos sobre a aflição da família para a compra do mês e da sobrevivência até a safra, apareceram declarações como "o ser humano sempre quer mais", mostrando que as necessidades humanas não se restringem ao básico para alimentação. Apareceram 
depoimentos que apontam a necessidade de ter lazer e outros tipos de consumo, como ir à praia ou ao cinema, comprar livros e roupas. Mais uma vez, vale lembrar que isso exclui os depoimentos de assalariados rurais:

"Se a gente tivesse dinheiro suficiente pra comprar tudo que a gente precisasse, né".

\section{Ficar sem nenbum dinheiro}

O conceito "Ficar sem nenhum dinheiro" foi interpretado como "Não ter dinheiro para nada". Ficou claro no grupo que, na comunidade rural aqui representada, poucas pessoas têm acesso ao dinheiro, pois estabelecem muitas relações de troca e o utilizam nas compras mensais tão logo o recebem. No Quilombo é uma "questão de sobrevivência a relação de troca de alimentos produzidos". Portanto, apesar de contraditório, o depoimento que melhor expressa a discussão desse conceito é o que diz:

"[...] a gente vive sem dinheiro, mas ficar sem ele não tem jeito".

\section{Insegurança alimentar}

"Insegurança alimentar" significa "não ter condições mínimas (renda, saúde, educação e habitação) para garantir a produção" ou "falta de estabilidade de trabalho e renda", ou ainda "não ter segurança de que vai ter dinheiro ou trabalho suficiente para se comer no próximo mês", nas palavras dos grupos. Os depoimentos sobre esse conceito se mostraram condizentes em relação ao conceito de Segurança alimentar discutido anteriormente. Para as populações rurais escaparem dessa situação, revelaram utilizar estratégias relacionadas à organização das famílias, pois "tudo começa na família" e a verdadeira "segurança está no povo".

\section{Fome}

"É não ter nada, mas nada mesmo pra comer";

"Acho muito duro você falar, seu filho chegar e 'mãe tô com fome' e você falar não tenho, e não ter de onde tirar [..] eu já passei e sei como é triste";

"[...]porque a gente passava essa fome, né... de não ter onde morar, de não ter trabalho, de não ter condição de colocar as crianças na escola".
"A fome faz parte do sistema de escravidão",

"[...] fome pra mim é uma coisa hereditária que vem desde o começo do Brasil".

Os mesmos depoimentos das áreas urbanas, comoventes e carregados de dor, apareceram nas áreas rurais quando o conceito "Fome" foi discutido. Principalmente aqueles relacionados às experiências anteriores, como por exemplo, "eu já passei isso aí e sei o que é [...] Só que se naquele tempo eu fosse o que sou hoje, não passava fome" e que mostram certo aprendizado, que parece também estar relacionado ao fato de morar no campo:

"Acho que tem muitas famílias que passam fome, lá pro fundão e aqui mesmo no estado de São Paulo. Lá no norte você vê aquelas mães com aquele monte de filho, aqueles grãozinhos de feijão cozinhando no chão [...], aquele monte de caldo pra 10 pessoas, beber aquilo, o que aquilo resolve, meu Deus! Não resolve nada, aquelas crianças só têm barriga, aquilo lá é fome né, agora a gente não, a gente tem uma banana, tem uma mandioca, tem uma batata, tem o leite, tem um suco, você não vai passar fome, você passa necessidade de ter aquele alimento adequado. Eu já passei sim, com os meus filhos pequenos, eu já passei [o depoimento é interrompido nesse momento, porque a senhora $G$. começou a chorar]"

Todos ficaram em silêncio quando a senhora G. não conteve as lágrimas ao lembrar de sua história vivida. Em seguida, outro participante disse:

"Acho que fome é uma coisa complicada né, acho que se a gente fosse fazer uma discussão do que é fome no Brasil hoje, seria a falta de vergonha dos políticos deixar as pessoas passarem fome".

Depois desse depoimento a senhora G. retoma a palavra e diz:

"Aqui no Brasil não era pra ter nenhuma família assim passando fome, há quanto tempo vêm esses políticos falando [...] se eles tivessem feito mesmo desde o começo, eu tô com mais de 50 anos, é claro que não tinha ninguém nessa situação".

A partir desse momento as explicações para a fome, por parte da comunidade rural, mostraram a sua relação com o sistema econômico em que estamos inseridos: 
(In) segurança alimentar: experiência de grupos focais, Sampaio et al.

"Que nem começou a escravidão, aos poucos mudou, veio a abolição, mudou sim, só que tirou só dos negros e botou todo mundo, agora não é só o negro, é o branco, todo mundo é escravo, a fome faz parte do sistema, se não tiver fome não tem o sistema"

Eles apresentam no discurso a "falta de vergonha" dos dirigentes e a necessidade de todos terem acesso à cidadania. "Fome de justiça" apareceu no depoimento de quem já passou por isso e descobriu estratégias para escapar da fome, como morar no campo, especificamente em um assentamento de reforma agrária, por exemplo:

"Esse negócio chamado reforma agrária que já deu certo em Sumaré que os grandes têm medo. Porque vai acabar com a fome deles. Lá no assentamento tem 200 famílias que nós demos apoio pra eles. Porque a gente já passou e sabe o que é fome, os caras estão lá esperando mais de 30 dias um pedacinho de terra pra eles trabalharem e acabarem com a fome [...]".

\section{Discussão}

Em linhas gerais, a experiência dos grupos focais com diferentes representantes de populações rurais do Estado de São Paulo ofereceu uma situação de comunicação completamente incomum, livre dos constrangimentos que pesam sobre seus cotidianos e abrindo alternativas que os incitaram a exprimir suas percepções sobre os conceitos anteriormente mencionados.

Ficou evidente nos depoimentos apresentados, especialmente em relação à discussão da palavra "fome", que grande parte dos participantes aproveitou essa situação como uma ocasião excepcional que lhes foi oferecida para testemunhar, fazer-se ouvir, levar sua experiência da esfera privada para a pública; uma ocasião também para se explicar, no sentido mais completo do termo, ou seja, de construir seu próprio ponto de vista sobre eles mesmos e sobre o mundo, e manifestar o ponto, no interior desse mundo, a partir do qual eles vêem a si mesmos e o mundo, e se tornam compreensíveis, justificados, e para eles mesmos em primeiro lugar.

Nessa direção, importa considerar também que esses grupos focais foram constituídos em grande medida por lideranças qualificadas, principalmente no que se refere aos representantes de assentados e de quilombolas que possuem história pregressa de organização política coletiva e que muitas vezes influenciaram o teor das discussões.

Em pesquisa sobre uma abordagem fenomenológica da fome, Freitas ${ }^{[23]}$ afirma que esse termo apareceu, em um primeiro momento, apenas na fala de mulheres e homens de diferentes unidades domésticas que participaram de lutas políticas pela melhoria do bairro. De modo similar ao que foi verificado na presente pesquisa, essas pessoas anunciaram a palavra "fome", segundo a referida autora, "nos quadros de um contexto social e político, de modo claro, permitindo uma compreensão objetiva deste fenômeno na sociedade e, em especial, no bairro onde habitavam" ${ }^{[23]}$ (p.64).

A análise das falas dos participantes desses grupos focais, em linhas gerais, gerou indicativos para o entendimento da questão da Segurança, insegurança alimentar e fome, de fato, como uma questão política cada vez mais importante no contexto brasileiro, da mesma forma como foi considerada nos EUA, durante alguns anos, de acordo com a história do USDA Core Food Security Module apresentada no presente trabalho.

No final da década de 80, contrariando a premissa de que a fome é uma percepção subjetiva e que, por esse motivo, não pode ser medida por meios diretos, Radimer et al. ${ }^{[8]}$ demonstraram a possibilidade de mensuração dessa condição, de forma válida, confiável e direta nos domicílios, por meio de escalas. O objetivo da pesquisa qualitativa seguida por pesquisa quantitativa (quali-quanti) desses autores foi, num primeiro momento, desenvolver uma compreensão da fome a partir da perspectiva de mulheres que vivenciaram essa situação para depois, num segundo momento, construir e avaliar indicadores, que por meios diretos mensurassem esse conceito em populações similares. $\mathrm{Na}$ fase qualitativa da pesquisa, foram identificados componentes de insegurança alimentar, em âmbito domiciliar e individual, relacionados à quantidade e qualidade de alimentação, a aspectos psicológicos e sociais, e ao entendimento da fome como um processo administrado (managed process) visando à sobrevivência. Este trabalho teve grande impacto nas discussões acerca do tema na época, fornecendo as palavras-chave e conceitos que integraram, posteriormente, a base da Escala Norte-Americana de Segurança Alimentar. 
Para pontuar as semelhanças e diferenças que reforçam a pertinência do uso deste método de avaliação da insegurança alimentar e fome para o contexto brasileiro, são apresentados a seguir alguns dos fragmentos qualitativos de Radimer et al. ${ }^{[8]}$ para comparação.

As semelhanças em relação à presente pesquisa referem-se, principalmente, às conceituações em função da qualidade ("unsuitable food" e "inadequate diet") e da quantidade da alimentação ("food depletion" e "insufficient intake"), observadas por esses autores em fragmentos tais como: "The children didn't have fruit (or juice, or vegetables, or milk, or meat)"; "You can miss a meal and not be bungry. But when it's not according to your own will, own volition [...] that you have to miss, or eat only a little because you don't have anything to eat, that's hunger" ${ }^{[8]}$ (p.38S).

Vale ressaltar que essas semelhanças em relação à qualidade e quantidade da alimentação também foram encontradas na pesquisa de Canesqui ${ }^{[24]}$, que foi realizada com o objetivo de analisar a organização e a realização das práticas alimentares cotidianas de famílias de trabalhadores que migraram da área rural para o município de Paulínia nos anos 70. Segundo essa autora, "Ter apenas arroz.com feijão no prato, desprovido de 'mistura', também simboliza a dieta empobrecida e monótona, enquanto a sua diversificação, segundo as entrevistadas dos dois estudos, traduzia a dieta mais rica, farta, e melhores condiçoes de vida" ${ }^{[24]}$ (p. 194).

Outra semelhança dos fragmentos da presente pesquisa com aqueles identificados por Radimer et al. ${ }^{[8]}$ diz respeito ao componente psicológico da insegurança alimentar, ou seja, à questão da ansiedade e/ou da preocupação de que o alimento possa vir a faltar no domicílio, notada naquele país no início dos anos 90 ("food anxiety", "feeling deprived" e "lack of choice"), tais como: "When you would get up in the morning, you would begin to worry if you were going to have enough food to make dinner, and if you did have enough food to get through day, what about tomorrow?" ${ }^{[8]}$ (p.39S). Os seguintes fragmentos mostram essa realidade presente também nos grupos focais aqui estudados:

“[...] segurança alimentar pra mim é isso, né... é uma coisa que não é seguro, por exemplo, não tem segurança que no fim do mês eu tenha dinheiro pra fazer compra, será que o meu trabalho vai me dar essa oportunidade?";
"A questão (é) que o Brasil hoje não tem estabilidade, eu vejo assim tem muitas pessoas que não têm segurança, eu tenho para esse mês, mas e o mês que vem? Segurança pra mim é essa coisa de ficar seguro, por exemplo, quem tem a terra pra trabalhar com a terra ele está seguro, porque a terra sendo o alimento, agora quem não tem aonde plantar, né [...] é não ter estabilidade";

"[...] eu me preocupo todo dia, mesmo que tem alguma coisa em casa, eu penso ai meu Deus será que vai faltar? Eu me preocupo todo dia, eu levanto da cama me preocupando, agora quem tem se preocupa em gastar, mas a gente não".

Nesse sentido, Canesqui [24] (p. 193) também afirmou que "Comer 'bem' on o 'menos mal' possivel é preocupação constante e obrigação moral, à medida que se privar é se expor a um conjunto de sançoes físicas e sociais: da fome à doença e à indisposição para trabalhar".

Ainda nesse contexto, em uma pesquisa qualitativa realizada no Estado da Bahia por Santos et al. ${ }^{[25]}$ sobre mulheres beneficiárias do Programa Bolsa Família, as participantes dos grupos focais falaram sobre o conforto de se ter a certeza de receber uma renda, e sobre a segurança que sentem em fazer planos para sua aplicação. Esses achados também lembram o componente psicológico identificado por Radimer et al. ${ }^{[8]}$.

Em relação à inadequação do padrão alimentar do adulto que deixa de se alimentar para garantir a dieta das crianças, o que para Radimer et al. ${ }^{[8]}$ era "Parents begin to skip meals first to spare the children", os participantes dos grupos focais expuseram, entre outras observações:

"Agora o que as famílias geralmente fazem, assim, no sítio, quem tem dificuldade de alimentação, diminui a alimentação. Geralmente os pais comem menos pra deixar para os filhos, e vão tentando manter o estoquinho pequeno, geralmente as famílias fazem, né... inventam algumas coisas, por exemplo, substituir o arroz pela mandioca, ou outras coisas em abundância na época, não deixa de ser uma estratégia, uma estratégia familiar".

De forma similar, para Canesqui ${ }^{[24]}$ (p.193), "condensa-se nos discursos a dimensão moral de prover e proteger a prole [. . .] A superação da fome, da desnutrição dos filhos [...] era trunfo moral exibido nos discursos da antiga 
(In) segurança alimentar: experiência de grupos focais, Sampaio et al.

geração $[\ldots]$ ”

Por fim, o componente social das conceitualizações encontradas por Radimer et al. ${ }^{[8]}$ como "unacceptable means of food acquisition", foi percebido também em fragmentos tais como os relacionados a seguir, que demonstram a escolha de um caminho, por meio de trabalho na agricultura, como importante estratégia alternativa a outros meios socialmente inaceitáveis para aquisição de alimentos.

"Quando eu tô vendendo alface, repolho lá na cidade, aí a gente sente a reforma agrária de perto, vê nas favelas que eles não têm o que comer, vê se o governo abre um parênteses e em vez desses meninos virarem bandidos, eles têm no que trabalhar [...]"

Ou, ainda, referindo-se à palavra "fome" com uma consciência política em prol de um direito, com uma visão social crítica, como por exemplo:

" [...] a gente tem fome, hoje eu sinto fome, mas não de comer, fome de justiça [...]".

Mostrando claramente estratégias que levaram a uma vida mais digna:

"isso nos fez que indo pra terra criasse essas condições, que de fato criou, hoje todo mundo tem casa, telefone, televisão, que há um tempo atrás onde a gente morava, em terreno da prefeitura, favela [...], então fome pra gente está muito relacionada com a melhoria das condições pra gente, tá passando fome hoje é não ter as condições que a gente tem aqui na terra".

A principal diferença observada em relação aos resultados obtidos por Radimer et al. ${ }^{[8]}$ contudo, esteve relacionada à ênfase atribuída à questão dos alimentos seguros, livres de agrotóxicos, pesticidas e da necessidade de consumo de produtos orgânicos, mencionada anteriormente pelos representantes de comunidades rurais paulistas que participaram dos grupos focais aqui analisados.

\section{Conclusões}

Embora a Escala Brasileira de Insegurança Alimentar (EBIA) se tenha originado de uma escala elaborada em distinto contexto sócio-cultural (Estados Unidos), a fase qualitativa de sua validação no Brasil indicou que os mesmos conceitos estão presentes, também, nas falas de brasileiros, que relataram experiência de insegurança alimentar e fome. A análise das discussões e, portanto, das falas, nos grupos focais, sobre conceitos pré-definidos e experiências de enfrentamento da situação de insegurança alimentar e fome, permitiu identificar similaridades com os depoimentos que deram origem à Escala NorteAmericana de Segurança Alimentar (USDA Core Food Security Module).

Essas contribuições dos participantes dos grupos focais rurais de São Paulo, bem como aquelas registradas pelos participantes de grupos focais rurais de outras quatro regiões do país, compuseram os procedimentos de validação quali-quantitativa da Escala Brasileira de Insegurança Alimentar e permitiram a estruturação de um único instrumento de medida, aplicável à população brasileira, seja ela rural ou urbana. Isso permitiu que a EBIA fosse utilizada pelo IBGE em sua Pesquisa Nacional por Amostra de Domicílios - PNAD $2004{ }^{[26]}$, proporcionando o primeiro diagnóstico, no Brasil, de segurança e insegurança alimentar com abrangência nacional.

\section{Agradecimentos}

Os autores agradecem a todas as pessoas que, no seminário realizado e em reuniões de trabalho para a construção desta parte da pesquisa, ofereceram o melhor de seu conhecimento e compromisso social. Agradecem, especialmente, aos participantes dos grupos focais, que agregaram experiências e conhecimentos fundamentais para a realização do trabalho. Nosso reconhecimento e respeito são ainda maiores por sabermos que cada palavra proferida refletia, de fato, a experiência de viver, ou de ter vivido, o cotidiano com insegurança alimentar ou fome. Agradecemos, também, o apoio financeiro e técnico da Organização Pan-Americana de Saúde - OPAS/Brasil (SA-9811/ 2003), do Ministério do Desenvolvimento Social, da UNESCO (Norte/Nordeste, SA-3382/2004) e da Fundação de Amparo à Pesquisa do Estado de São Paulo - FAPESP (02/09.332-1).

\section{Referências bibliográficas}

[1] Bickel G et al. Guide to measuring Household Food Security in the United States, revised 2000. USDA, Food and Nutrition Service, August 2000. Disponível em: www.ers.usda.gov/publications/fanrr11-1/fanrr11 1b.pdf [Acesso em 26 jun. 2006]. 
[2] Bickel G \& Andrews M. A evolução do Programa de Cupom Alimentação e a mensuração da fome nos Estados Unidos. In: Takagi M, et al. (orgs). Combate à fome e à pobreza rural. São Paulo: Instituto Cidadania; 2002. p.34-74.

[3] USDA, Food and Consumer Service, Office of Analysis and Evaluation. Food Security Measurement and Research Conference: Papers and Proceedings. Alexandria, Virginia, 1995.

[4] Basiotis P. Validity of self-reported food sufficiency status item in the U. S. Department of Agriculture's food consumption surveys. American Council on Consumer Interests $38^{\text {th }}$ Annual Conference: The Proceedings (V.A. Haldeman, ed.). Columbia, MO, 1992. APUD: Bickel G \& Andrews M. A evolução do Programa de Cupom Alimentação e a mensuração da fome nos Estados Unidos, 33-74. In: Takagi, M., Graziano da Silva, J. Belik, W. (Orgs). Combate à fome e à pobreza rural. São Paulo: Instituto Cidadania; 2002.

[5] Wehler CA et al. The Community Childhood Hunger Identification Project: a model of domestic hunger-demonstration project in Seattle, Washington. J. Nutr. Educ. 1992;24:29S-35S.

[6] FRAC. Community Childhood Hunger Identification Project. A survey of childhood hunger in the United States. Food Research and Action Center, Washington, D.C. March 1991.

[7] Radimer KL et al. Development of indicators to assess hunger. Journal of Nutrition. 1990; Suppl:1544S-1548S.

[8] Radimer KL et al. Understanding hunger and developing indicators to assess it in women and children. J. Nutr. Educ. 1992;24:36S-45S.

[9] Campbell CC. Food Insecurity: a nutritional outcome or a predictor variable? Journal of Nutrition. 1991;121:408-15.

[10] CONSEA. II Conferência nacional de segurança alimentar e nutricional. Relatório Final. Pernambuco; 2004.

[11] Pérez-Escamilla R. Experiência internacional com a escala de percepção de insegurança alimentar. Cadernos de Estudos. Desenvolvimento Social em
Debate, 2005;(2):14-27.

[12] Segall-Corrêa AM et al. (In) segurança alimentar no Brasil: Validação de metodologia para acompanhamento e avaliação da segurança alimentar de famílias brasileiras. URBANO/RURAL. Campinas; 2004. [Relatório Técnico]. Disponível em: http:// www.opas.org.br/publicac.cfm.

[13] Sampaio MFA et al. Validation of the USDA food insecurity module: rural areas in the state of São Paulo, Brazil: qualitative phase. The Faseb Journal. 2005;19(5):A1349.

[14] Scrimshaw SCM \& Hurtado E. Focus groups. In: Rapid assessment procedures for nutrition and primary health care: anthropological approaches to improving programme effectiveness. UCLA Latin American Center Publications, University of California, Los Angeles [Reference Series, 11], p.1519. Tokyo: UNICEF, 1987.

[15] Morgan DL. Focus groups in qualitative research. Londres: Sage; 1988.

[16] Morgan DL. Focus groups in qualitative research. 2. ed. Londres: Sage; 1997.

[17] Kreuger RA. Focus groups: a practical guide for applied research. Londres: Sage; 1988.

[18] Westphal MF et al. Grupos focais: experiências precursoras em programas educativos em saúde no Brasil. Boletim da Oficina Panamericana. 1996;120(6).

[19] Kitzinger J. Introducing focus groups. British Medical Journal. 1995;311:299-302.

[20] Gibbs A. Focus groups. Social Research Update. University of Surrey, Guildford, England: Winter; 1997. Disponível em: www.soc.survey.ac.uk/sru/ $\underline{\text { SRU19.html }}$

[21] Minayo MCS. O desafio do conhecimento: pesquisa qualitativa em saúde. São Paulo - Rio de Janeiro: Hucitec-Abrasco; 1996.

[22] Afonso MLM. Oficinas em dinâmica de grupo: um método de trabalho estruturado com pequenos grupos [apostilado]. São Paulo: Curso "Dinâmica de Grupo"; 1997. 
(In) segurança alimentar: experiência de grupos focais, Sampaio et al.

[23] Freitas MCS. Uma abordagem fenomenológica da fome. Revista de Nutrição. 2002;15(1):53-69.

[24] Canesqui AM. Mudanças e permanências da prática alimentar cotidiana de famílias de trabalhadores. In: Canesqui AM \& Garcia RWD (orgs). Antropologia e Nutrição: um diálogo possível. Rio de Janeiro: FIOCRUZ; 2005. p.167-210.

[25] Santos SMC et al. Mulher, mãe e provedora: a experiência das mulheres como beneficiárias de programas de transferência de renda no interior da Bahia. In: III Congresso Brasileiro de Ciências Sociais e Humanas em Saúde (ABRASCO), 2005, Florianópolis. Anais do III Congresso Brasileiro de Ciências Sociais e Humanas em Saúde. Florianópolis: Zanda Multimeios da Informação, 2005. v. 10.

[26] Instituto Brasileiro de Geografia e Estatística. Pesquisa nacional por amostra de domicílios. Síntese de indicadores 2004. Disponível em: http://www.ibge.gov.br/lojavirtual/ fichatecnica.php? codigoproduto $=8712$ [Acesso em 28 jun. 2006].

\section{Anexo} (1996)*

\section{“Jogo do Círculo" proposto por YOZZO}

As instruções para realização do jogo foram passadas da seguinte maneira:

1.Todos em pé, em círculo (voltados para dentro), de mãos dadas. Essa é a posição a ser encontrada ao final do jogo.

2.Todos continuam em círculo, porém agora voltados para fora, de mãos dadas.
3.O coordenador dá a seguinte instrução: "Vocês devem ficar de frente para o círculo, voltando à posição inicial sem soltar as mãos e nem ficar com os braços cruzados. Durante as tentativas não podem passar por cima dos braços".

4.Num primeiro momento tentarão sem verbalização.

5.Após um determinado tempo, permitir a verbalização.

6.Término do jogo, quando a solução for encontrada.

\section{Comentários.}

\section{Descrição do andamento do Jogo do Círculo}

Após as instruções para o Jogo do Círculo, o grupo fez inúmeras tentativas em vão. Ao inserir a instrução para que se utilizassem da verbalização, o grupo começou a se comunicar, sendo que uma das participantes conseguiu encontrar a solução e todos a seguiram. No final, aplaudiram-se.

Nos comentários, fizeram observações sobre as dificuldades encontradas, as tentativas frustradas e sobre a maior facilidade da execução a partir do momento em que a comunicação se fez possível.

Ao final desses comentários, o coordenador reafirmou a importância dessa aprendizagem para a continuidade dos trabalhos durante o dia. Tendo em vista o resultado da boa comunicação entre o grupo, o coordenador ressaltou que, assim como aconteceu durante o jogo, nas atividades subseqüentes do dia, a participação de cada um, com suas características próprias, era parte fundamental do trabalho.

\footnotetext{
* Yozzo R.Y.K. 100 jogos para grupos. Uma abordagem psicodramática para empresas, escolas e clínicas. São Paulo: Agora; 1996.
} 